\title{
El rechazo de las mujeres mayores viudas a volver- se a emparejar: cuestión de género y cambio social
}

\author{
Juan LÓPEZ DOBLAS \\ Universidad de Granada \\ jdoblas@ugr.es \\ María del Pilar DíAz CONDE \\ Universidad de Granada \\ mpdiaz@ugr.es \\ Mariano SÁNCHEZ MARTÍNEZ \\ Universidad de Granada \\ marianos@ugr.es
}

Recibido: 23-04-2014

Aceptado: 08-06-2014

\section{Resumen:}

El objetivo de este artículo es indagar sobre las actitudes personas mayores viudas en España respecto a la posibilidad de formar otra pareja, sea celebrando otro matrimonio o conviviendo con alguien sin llegar a casarse. Lo hacemos desde una óptica sociológica, aplicando metodología cualitativa y, en concreto, la técnica del grupo de discusión. De los resultados cabe destacar que iniciar una relación de pareja despierta un interés muy escaso, particularmente entre las mujeres, por diversas razones. Aunque en algunas de ellas influyen valores tradicionales (como, por ejemplo, el no querer poner a nadie en el lugar de su primer marido o el temor a recibir la crítica familiar y social), cuenta tanto o más otra serie de motivaciones (como el renunciar a emparejarse con alguien mayor que ellas, el mantener su libertad y su independencia, la defensa de su autonomía) que permiten entrever la existencia de un importante cambio en el modo en que las mujeres mayores conciben la vejez y las relaciones entre los géneros.

Palabras clave: vejez; viudez; mujer; volverse a casar; uniones de hecho; cambio social; metodología cualitativa 


\title{
Older widows refusal to repartnering. Gender and social change question
}

\begin{abstract}
The aim of this paper is delving into the attitudes by widowed older people in Spain around the possibility of repartnering, whether it is through marriage or mere cohabitation. A qualitative methodology with a sociological lens, in the way of discussion groups, has been implemented. Main research findings show that widowed older persons -particularly women, are scarcely interested in initiating a relationship with a new partner. There are diverse reasons for this lack of interest. In some cases, older widows are just bounded to traditional moral rules such as not allowing anyone to seize the place of their first husband, or a fear of familial and social criticism. However, there are more powerful reasons: unwillingness to partner with someone who is older, a wish to preserve their own freedom and independency, or a determination to safeguard their autonomy. These reasons allow us to glimpse an important change in terms of how older women understand bothold age and relationships between genders.
\end{abstract}

Keywords: old age; widowhood; women; remarriage; cohabitation; social change; qualitative methodology

\section{Referencia normalizada}

López Doblas, J.. (2014). "El rechazo de las mujeres mayores viudas a volverse a emparejar: cuestión de género y cambio social”. Política y Sociedad, Vol 51, Núm. 2: 507-532

Sumario: Introducción. 1.Literatura internacional. 2.Objetivos y metodología. 3.Resultados. 4.Discusión y conclusiones. 5.Bibliografía 


\section{Introducción}

En España el interés sociológico por la formación de parejas en las edades avanzadas ha resultado muy escaso, prácticamente nulo, hasta hace bastante poco. Quizás ello se deba a su baja incidencia estadística o a que nos encontramos con un grupo de población que hasta ahora no ha sido demasiado considerado dentro de la disciplina. Excepcionales fueron las aportaciones de dos estudios sobre las mujeres viudas realizados por Alberdi y Escario a finales de los años ochenta: en el primero, de tipo cualitativo, descubrieron que las de mayor edad no piensan en volverse a casar puesto que "toda su vida está justificada y realizada en el matrimonio que tuvieron” (Alberdi y Escario, 1986:87); en el segundo, abordando también las actitudes hacia una posible relación, corroboraron por encuesta que "las expectativas hacia una nueva vida en pareja no forman parte de los deseos de las viudas como una forma de reorganización de sus vidas", máxime entre aquéllas que estuvieron más tiempo de casadas (Alberdi y Escario, 1990:89).

Pero habríamos de esperar bastante para disponer de más referencias bibliográficas. En la pasada década, han aparecido trabajos que, de un modo u otro, prestan atención a las personas que, tras haber vivido una experiencia marital previa, vuelven a casarse o bien optan por la cohabitación. Algunos de ellos se centran, explícita o implícitamente, en las personas en edad reproductora. Castro (2003:107), por ejemplo, confirma el auge de los "matrimonios reincidentes" (por el aumento del divorcio) y su mayor frecuencia entre los hombres, pero orienta su análisis sobre todo hacia individuos jóvenes y de mediana edad. Interesantes también son las reflexiones de Martínez (2009) sobre nupcialidad y cambio social, pero sin llegar tampoco a implicar en ellas a las personas mayores. Lo mismo ocurre en el artículo de Castro y Domínguez (2008) sobre las uniones de hecho, así como en el de Miret (2007), comparando éstas con los matrimonios. Domínguez y Castro (2013), a vueltas con el auge que la cohabitación parece estar cobrando en España, limitan de nuevo su análisis a las personas (mujeres) de 15 a 56 años.

Otros trabajos sí que han considerado los procesos de emparejamiento a edad avanzada, si bien reservándoles un número limitado de páginas. Entre ellos destaca el de Meil (2003:132), que indaga sobre "las parejas de hecho en la tercera edad": tras admitir la poca información estadística que hay en España sobre las mismas, utiliza algunos datos de encuesta para sostener que poseen un alcance mucho más limitado que en los países del centro y norte de Europa; y asegura que esas parejas las forman en su gran mayoría personas separadas o divorciadas y rara vez viudas. El estudio de Iglesias de Ussel et al. (2001:207), por su parte, sostiene que la formación de otra pareja supone un recurso que las personas viudas apenas consideran como medio para "vencer a la soledad". En este mismo sentido, López Doblas (2005) concluye que las mujeres mayores solas ni siquiera llegan a plantearse seriamente buscar pareja, algo que confirman Sánchez Vera et al. (2009) por encuesta: tan sólo el 7,69\% de los viudos y el 2,96\% de las viudas inician otra relación.

Con mayor hondura analiza el fenómeno Spijker (2007:44): al abordar las trayectorias familiares de las personas tras enviudar percibe que la posibilidad de 
emparejarse de nuevo es ampliamente rechazada por "motivos personales" y no tanto por obstáculos culturales, religiosos o sociales. Idéntico hecho ha sido comprobado en dos estudios que utilizan encuesta: el de Ayuso (2011), según el cual apenas el 4,3\% de las mujeres viudas rehacen su vida de pareja, sea mediante otro matrimonio, una unión de hecho o una relación sin convivencia de continuo, y el de Sánchez Vera y Bote (2007:139), quienes plantean lo siguiente en sus conclusiones: "la cuestión sería conocer por qué, en una sociedad en cambio, permisiva y tolerante en muchos aspectos, donde la imagen de los mayores ha mejorado y se han instalado la autonomía y la independencia, no cristalizan más relaciones”. De este repaso de la literatura que hemos efectuado sobre el tema del emparejamiento en edades avanzadas cabe concluir que, en nuestro país, existe un déficit de información y análisis sociológico al respecto que el presente trabajo quiere contribuir a paliar.

\section{Literatura internacional}

Al contrario de lo que ha sucedido en España, en países como Estados Unidos, Canadá, Francia, Reino Unido u Holanda, la formación de relaciones de pareja en las edades avanzadas sí que ha motivado durante las últimas décadas una cantidad elevada de publicaciones. Se ha generado una base importante de conocimiento sobre la posibilidad de que las personas mayores sin pareja establezcan una unión, sea vía matrimonio, conviviendo sin llegar a casarse o mediante otra clase de vínculo más flexible, como las relaciones living apart together (LAT), definidas por De Jong (2002:77) como "una relación de pareja en la cual sus miembros continúan residiendo en sus viviendas respectivas, e intermitentemente comparten los hogares, sea durante los fines de semana o de otra manera”. A continuación procedemos a repasar el conocimiento internacional disponible sobre las dos primeras de esas modalidades de emparejamiento, la nupcial y la cohabitación sin casarse, pues entrañan por lo general un mayor grado de compromiso que el que suele darse en las relaciones LAT y, además, porque esas dos opciones, para el caso de España, son precisamente las que constituyen el núcleo del presente trabajo.

\subsection{Sobre la posibilidad de que las personas mayores sin pareja decidan casar- se}

En muchos países occidentales el interés sociológico por las segundas nupcias se activó en los años ochenta, a raíz básicamente del alza que estaba registrando el divorcio. En Estados Unidos, por ejemplo, en 1974 se constató un hecho insólito pero que resultaría habitual en adelante: el número de matrimonios disueltos por divorcio superó al de extinguidos por viudez (Glick, 1980); volver a casarse después de haber sufrido una ruptura matrimonial pasó a constituir "un aspecto muy común en la experiencia familiar americana” (Bumpass et al., 1990:754), hasta el 
punto de que alrededor del $40 \%$ de las bodas celebradas hacia finales de la década de 1980 no suponían su primer matrimonio para uno de los dos contrayentes (Clarke y Wilson, 1994; Coleman y Ganong, 1990). En términos generales, afirma Sassler (2010:557), "la naturaleza y los procesos de formación de las relaciones íntimas han cambiado de manera notable en las últimas décadas”.

Aunque la investigación sobre quienes se casan de nuevo se ha orientado más hacia las personas en edad reproductora, lográndose un abundante conocimiento sociológico acerca de ellas (Coleman et al., 2000), también han ido apareciendo estudios sobre la posibilidad de que lo hicieran o no las personas mayores sin pareja, sobre todo viudas o divorciadas. Entre esos estudios algunos abordan singularmente la viudedad, como el de Smith et al. (1991), en Estados Unidos, poniendo de relieve cómo el tiempo transcurrido desde la muerte del cónyuge juega en contra de la probabilidad de celebrar un nuevo enlace, o los mayores beneficios que los viudos obtienen del mismo en comparación con las viudas. Conclusiones similares arroja la investigación de Wu (1995), en Canadá. Y en el caso del Reino Unido, Davidson (2002:47), analizando también los procesos de emparejamiento de las personas mayores viudas, construye un modelo teórico sobre las diferencias de género, basado en la salud y la economía como recursos personales; su investigación cualitativa concluye que, para los varones, la enfermedad no supone un obstáculo significativo a la hora de emparejarse siempre y cuando gocen de una buena posición financiera; entre las viudas, en cambio, "la presencia de dinero no es tan importante como disfrutar de una buena salud".

Carr (2004:1064), investigando por encuesta en Estados Unidos, efectúa otra relevante aportación: la importancia que tiene para los viudos el apoyo social que reciben de los amigos en cuanto al deseo que pudieran tener de encontrar pareja; cuando disponen de altos niveles de sostén emocional, los viudos y las viudas "no difieren en sus deseos de establecer una relación romántica tras la pérdida del cónyuge", pero cuando existen bajos niveles de apoyo, los primeros sí que tienen mucha más probabilidad que las segundas de interesarse por buscar a alguien y volverse a casar algún día. Resulta muy llamativo que la sobreabundancia de mujeres mayores sin pareja tenga repercusiones contrarias según el sexo: según el estudio de Stevens (2002), realizado en Holanda, en el caso de los viudos implica contar con más opciones para rehacer su vida matrimonial; en el de las viudas, sin embargo, disponer potencialmente de unas redes de amistad más abundantes, lo cual no haría sino reforzar su negativa a emparejarse.

Varias investigaciones llevadas a cabo en Estados Unidos descubren nuevos hechos que consideramos de gran interés. Bograd y Spilka (1996), comparando a personas viudas o divorciadas de distintas edades que se han vuelto a casar, encuentran una mayor satisfacción con ese nuevo matrimonio entre quienes dan ese paso a una edad avanzada (60-75 años) que entre quienes lo hacen a una edad inferior (3045 años), sobre todo si son hombres. A pesar de ello, el deseo de casarse cuando no se tiene pareja es mucho menor entre las personas longevas que entre las de edad intermedia, y no sólo porque en líneas generales lleven más tiempo sin ella sino porque, como añaden Mahay y Lewin (2007:720), “tampoco tienen la sensación de 
que las ganancias del matrimonio vayan a significar más que sus costes”. Esto ha sido subrayado, sobre todo, en trabajos que han abordado en particular la viudedad femenina (Moorman et al., 2006; Talbott, 1998). En cualquier caso, ya sea para los varones o para las mujeres, la probabilidad de casarse de nuevo es significativamente más elevada entre las personas mayores divorciadas que entre las viudas, tal y como han concluido estudios realizados en Canadá (Burch, 1990) y el Reino Unido (Davidson, 2002).

Por último, de las segundas (o sucesivas) nupcias conviene destacar que prácticamente todas las investigaciones que las han analizado coinciden en afirmar que resultan menos frecuentes entre las mujeres que entre los varones: tanto las realizadas en Norteamérica (Van den Hoonaard, 2001; Wilson y Clarke, 1992, Bulcroft et al. 1989) como en países europeos tan diversos como Francia (Delbès y Gaymu, 2000), Rusia (Buckley, 1996), Holanda (De Jong, 2004) o el Reino Unido (Davidson, 2001). Es muy significativo, además, que tal circunstancia haya sido observada en todas las sociedades del pasado; demógrafos e historiadores de la familia aseguran que las bodas con participación de viudos fueron siempre mucho más habituales que las que implicaban a viudas (Fauve-Chamoux, 2010; Breschi et al., 2009; Schmidt, 2007; McQuillan, 2003; Elman y London, 2002; Moring, 2002; Van Poppel, 1995; Blom, 1991; Bideau, 1980).

\subsection{Sobre la posibilidad de que las personas mayores sin pareja opten por cohabitar sin casarse}

Las uniones de hecho llevan décadas incrementándose en las sociedades occidentales $\mathrm{y}$, aunque sean comparativamente más frecuentes entre las personas en edad reproductora, también están adquiriendo cierta expansión entre las mayores (Brown y Kawamura, 2010; Moustgaard y Martikainen, 2009; Calasanti y Kiecolt, 2007; Delbès y Gaymu, 2005; De Jong y Peeters, 2003; Cooney y Dunne, 2001; Chevan, 1996). En Estados Unidos, que es donde más se ha investigado sobre ellas, Cherlin (2010) calcula que el 3,3\% de las mujeres cohabitantes y el 4,6\% de los varones cohabitantes superan los 65 años de edad. Aun así, y tal como reconocen Brown et al. (2012:788), "entre las personas mayores la cohabitación es todavía relativamente poco común”. Otro reciente trabajo, realizado por Lin y Brown (2012), confirma que la mayoría de los denominados baby boomers (personas nacidas entre 1946 y 1964, en el baby boom que sucedió a la Segunda Guerra Mundial) sin pareja optan por vivir en solitario, rechazando tanto la cohabitación como el matrimonio.

A juicio de Sassler (2010:560), "la decisión sobre ingresar en una relación romántica, las preferencias sobre las cualidades de la pareja y las metas de tales relaciones varían mucho en el curso de la vida". Las uniones de hecho, en concreto, tienen características singulares en las edades avanzadas, algunas de ellas en claro contraste con respecto a las que se forman en etapas previas de la vida. Por ejemplo, la investigación de Brown y Booth (1996) con personas de 19 a 48 años destacó la importancia que entraña para la calidad y la estabilidad de sus relaciones el que 
haya planes futuros de matrimonio. Sin embargo, tal cosa no parece transcendental entre las personas mayores. Lo afirman King y Scott (2005:282), cuyo estudio aporta dos conclusiones fundamentales: una, que "las personas mayores cohabitantes disfrutan de niveles de calidad relacional superiores a los adultos jóvenes, en todas las dimensiones examinadas" (justicia en la pareja, tiempo compartido, discrepancias, conflictos y violencia); otra, que barajan menos planes para casarse, lo cual significa que en las edades avanzadas las uniones de hecho suelen ser, más que en las inferiores, una alternativa real al matrimonio y no su mero preludio. Es una tesis defendida asimismo por Brown y Kawamura (2010), quienes recalcan que la motivación para cohabitar resulta diferente en cada etapa de la vida.

¿Y quiénes se muestran más propensos a cohabitar a edad avanzada, los hombres o las mujeres? Brown et al. (2012) constatan la menor incidencia de las uniones de hecho entre las mujeres, particularmente entre las viudas; también Chevan (1996:665), quien vincula, por otro lado, este tipo de relaciones con una peor situación económica: "quizás las personas mayores con ingresos altos se casan, mientras que las personas mayores con bajos ingresos tienden a la cohabitación”. A conclusiones parecidas llegan Brown et al. (2006), afirmando que tienden a cohabitar en menor medida las mujeres que los varones y que, en general, son personas con recursos económicos per cápita inferiores a quienes vuelven a casarse, así como con un apoyo social más vulnerable en el caso de romperse la relación. De Jong y Peeters (2003) sostienen que emparejarse a una edad elevada, y hacerlo mediante una forma de vida no tradicional, tiene un efecto negativo sobre el entramado social. Quizás sea, añade De Jong (2002:74), porque “casarse de nuevo después de enviudar es el acuerdo que, en general, más aprobación cultural ha tenido durante los siglos".

En este sentido, la investigación de Moustgaard y Martikainen (2009:515), realizada en Finlandia, confirma la tesis de que "las personas mayores que cohabitan tienen menos ventajas que sus homólogas casadas". Las uniones de hecho protegen menos que las de derecho, y no sólo en lo económico y en lo social sino incluso en la salud. Según Noël-Miller (2011), las personas mayores que cohabitan cuentan con menos probabilidades de recibir cuidados por parte de la pareja que las que se hallan casadas, al existir menos sentimientos de obligación y de responsabilidad. Brown et al. (2005:28), valorando la importancia del estado civil sobre la incidencia de la depresión en las edades avanzadas, encuentran no obstante diferencias de género: tras observar una mayor prevalencia de la enfermedad entre las personas que cohabitan que entre las casadas, matizan que la asociación estadística resulta muy fuerte en el sexo masculino mientras que apenas se produce en el femenino; su conclusión es que "la cohabitación no provee al hombre de los mismos beneficios respecto a la salud mental que el matrimonio". Luego, cohabitar no equivale a estar casados, en efecto, sobre todo para los varones.

Una de las principales conclusiones que podemos extraer de esta revisión de la literatura sobre el tema es que entre las personas mayores viudas volverse a emparejar despierta mayor interés para los hombres que para las mujeres. O, dicho con más exactitud, buscar a otra persona con quien casarse o convivir genera un rechazo 
particularmente hondo entre ellas; y no nos referimos sólo a las mujeres que residen en otros países sino, tanto o más si cabe, a las propias viudas españolas. Recordemos que varios estudios han apuntado lo poco dispuestas que se muestran a ello (Ayuso, 2011; Sánchez Vera et al., 2009; Meil, 2003). Ahora bien, dichos estudios, al basarse en encuestas o utilizar datos secundarios de naturaleza cuantitativa en sus análisis, han puesto de manifiesto lo infrecuente que resulta el fenómeno, pero apenas han profundizado en las razones subjetivas que lo motivan. De ahí que esté justificado un artículo como éste, con el objetivo y el enfoque metodológico que pasamos a presentar.

\section{Objetivo y metodología}

El objetivo de este artículo es analizar el discurso de las personas mayores viudas sobre la posibilidad de rehacer o no su vida de pareja, sea mediante un nuevo matrimonio o conviviendo con otra persona sin casarse. En concreto, centraremos nuestro interés no en aquellas personas que han vuelto a emparejarse, sino en las que teóricamente podrían hacerlo y, sin embargo, lo rechazan. El escasísimo número de viudos y sobre todo de viudas que rehacen su vida matrimonial en España (Sánchez Vera y Bote, 2007; Spijker, 2007) o bien deciden cohabitar (Meil, 2003) sugiere la necesidad de contar con una interpretación comprensiva que descubra los motivos personales de su postura, máxime cuando en la literatura internacional los procesos de emparejamiento suelen presentarse como una de las vías fundamentales por las cuales los actores sociales podrían aliviar problemas como el aislamiento social o el sentimiento de soledad (Watson et al., 2010; Moorman et al., 2006; De Jong y Peeters, 2003; De Jong, 2002; Davidson, 2001).

En respuesta a esta necesidad, vamos a mostrar algunos resultados de la investigación titulada 'Las personas mayores que viven solas', financiada por el Instituto de Mayores y Servicios Sociales (IMSERSO) y en cuya vertiente cualitativa empleamos la técnica del grupo de discusión. En su diseño efectuamos un muestreo de tipo estructural, basado en el sexo, el hábitat y la diversidad regional (Tabla 1). En total, realizamos ocho grupos de discusión.

Tabla 1. Grupos de discusión realizados

\begin{tabular}{|l|c|c|c|c|}
\hline & \multicolumn{2}{|c|}{ Varones } & \multicolumn{2}{c|}{ Mujeres } \\
\hline & Rural & Urbano & Rural & Urbano \\
\hline Asturias & GR1 & GR2 & GR3 & GR4 \\
\hline Andalucía & GR5 & GR6 & GR7 & GR8 \\
\hline
\end{tabular}

El trabajo de campo se realizó entre los meses de enero (Asturias) y junio (Andalucía) de 2009. Detallamos a continuación las localidades en las cuales se celebraron los grupos de discusión, su duración y algunos rasgos elementales de las personas que los compusieron: 
- GR1 (Moreda), nueve participantes: siete viudos, de 74, 77, 80, 84, 84, 85 y 92 años de edad; uno separado de 69 años y otro divorciado de 73 años. Su duración fue de 1 hora y 18 minutos.

- GR2 (Gijón), ocho participantes: seis viudos, de 70, 74, 78, 79, 90 y 95 años; uno divorciado de 81 años y uno soltero de 80 años. Duró 1 hora y 51 minutos.

- GR3 (Coaña), seis participantes, todas viudas; sus edades: 70, 70, 73, 77, 84 y 85 años. La duración fue de 1 hora y 48 minutos.

- GR4 (Oviedo), diez participantes, todas viudas: 71,71, 73, 73, 76, 77, 77, 78, 81 y 90 años de edad. Duración: 1 hora y 41 minutos.

- GR5 (Nerva, Huelva), ocho miembros: seis viudos, de 66, 74, 76, 80, 80 y 83 años; un soltero de 76 años y un separado de 68 años. Duración: 1 hora y 45 minutos.

- GR6 (Almería), seis participantes: cuatro viudos, de 69,73, 83 y 84 años; un soltero de 75 y un divorciado de 72. Su duración fue de 1 hora y 18 minutos.

- GR7 (Ronda, Málaga), once miembros: diez viudas, de 71, 72, 74, 75, 75, 78, 78, 78, 81 y 83 años y una soltera de 63 años. Duración: 2 horas y 6 minutos.

- GR8 (Sevilla), diez participantes: seis viudas, de 72, 76, 76, 78, 80 y 81 años; dos solteras, de 75 y 76 años; una separada de 75 y una divorciada de 68. Su duración fue de 1 hora y 35minutos.

La investigación giró en torno a la realidad familiar y social de las personas mayores que viven solas, que en su gran mayoría son viudas. Un objetivo crucial era conocer las razones por las cuales residían solas y no de otro modo, como por ejemplo conviviendo con familiares, ingresando en una residencia o formando otra pareja. La posibilidad de buscar a alguien para unirse en matrimonio o para cohabitar sin casarse constituyó, en este sentido, una cuestión ampliamente debatida en todos los grupos de discusión.

Tanto la moderación de los ocho grupos de discusión como su transcripción fueron tareas llevadas a cabo por los propios investigadores del proyecto, con el objeto de lograr la mayor calidad posible en los materiales de campo. En cuanto a la estrategia de análisis, los textos resultantes de la transcripción fueron codificados hasta encontrar, siguiendo un procedimiento inductivo, las categorías y los conceptos teóricos claves para interpretar el fenómeno. Seguimos las directrices de la Grounded Theory, formulada por Glaser y Strauss (1999), respecto al proceso de generación de teoría, tanto de tipo sustantivo como en última instancia formal, a partir de los datos empíricos. Como recomiendan también Strauss y Corbin (2002:13-14), no partimos de una "teoría preconcebida" para comprobarla sino de un área concreta de estudio como la que hemos expuesto para, después de sumergirnos en las informaciones obtenidas en el trabajo de campo, activar la creatividad investigadora con "la fundamentación de conceptos en los datos".

En palabras de Denzin y Lincoln (2012:90), "las interpretaciones cualitativas surgen de un proceso de construcción" que, en nuestro caso, hemos desarrollado formulando propuestas teóricas con base en nuestros materiales de campo, ilustradas con fragmentos literales obtenidos de las transcripciones. De esta forma, trata- 
mos de ajustarnos al modo de practicar la sociología reflexiva al que invita Bourdieu (2005:307), cuyo dictum es "ser capaz de comprometer apuestas teóricas muy altas mediante objetos empíricos muy precisos y a menudo aparentemente mundanos, si no irrisorios”. Nuestra apuesta teórica, como tendremos ocasión de comprobar en la parte culminante de discusión de los resultados, es la siguiente: el escaso interés que tienen las personas mayores viudas en volverse a emparejar, sobre todo las mujeres, responde a que son partícipes de un cambio social en las relaciones de género y en la concepción de la vejez.

\section{Resultados.}

\subsection{Es algo que no encaja en la vejez}

Las mujeres mayores viudas rechazan buscar pareja, en primer lugar, porque creen que es algo inapropiado para la gente de su edad. Aunque tienden a mostrar comprensión hacia aquellas personas que pierden el cónyuge siendo relativamente jóvenes y que, pasado un tiempo prudente, deciden buscar a alguien con quien rehacer su vida, critican a quienes tratan de hacer lo mismo habiendo cumplido ya setenta u ochenta años. Emparejarse, coinciden en señalar las viudas, es de no tener bien la cabeza dado que se estarían imitando, sin sentido, comportamientos juveniles en la vejez:

¿Entonces lo de buscar pareja...?

¿Buscar pareja? ¡Tienes que estar mal de aquí!

Ya lo creo.

¡De aquí!

Pero en el amor no existe la edad, ¿̇no?

¡Qué va, el amor!

A nuestra edad ya no hay amor. Eso es la gente joven (GR4:34).

El discurso femenino recalca que en la vida todo gran evento tiene su momento ideal de celebración, y tanto el del matrimonio como el del inicio de una convivencia de hecho no se encuentran en la vejez. En el discurso masculino no apreciamos tanto este matiz, quizás porque, cuando los hombres piensan en buscar pareja, no siempre tienen como referencia a mujeres coetáneas sino, a menudo, a otras más jóvenes. Para los viudos, el horizonte relacional resulta en potencia más amplio, y no únicamente en términos de edad sino incluso de nacionalidad:

Traes a una colombiana de esas y después qué, ¿te echa de casa?

Je, je, je.

Y llámate "papi, papi".

¿No es así? Traes a una colombiana y te echa de casa. Je, je, je, je.

¿Y no ha pensado usted en volverse a casar alguna vez? mujer.

Yo llevo viudo casi nueve años y sin embargo nunca se me pasó a mí buscar otra 
Eso dices: “voy a buscar una a Galicia para traerla para acá”, para así dejar la paga mía a...

Al Estado (GR1:21).

Las viudas dan por seguro que la relación habría de establecerse con un hombre mayor que ellas, o cuanto menos de su edad. Ven descabellado emparejarse con otro más joven puesto que creen poco probable que alguien que ronde por ejemplo los 50 años vaya a interesarse por ellas. Y si tal es la realidad, se cuestionan, ¿por qué habrían de fijarse ellas en un viejo? Se perciben así en clara desventaja respecto a los varones. Buscar pareja, en tales condiciones, no les resulta atractivo:

Pues yo tampoco, yo tampoco. Yo ahora tengo... como hemos dicho, tienes tus ventajas y no tienes tus ventajas, pero yo no me vería ahora... vamos, no lo soportaría, un hombre en mi casa al cabo de tanto; porque mira, cuando tú eres joven, te echas un novio, te casas, envejeces juntos, conoces todas sus cosas...

Sus faltas.

... Y él las tuyas. ¿Pero ahora mismo?, una persona que tú no has conocido...

Sí, sí, sí, sí.

... Pues si tú tienes setenta y tantos años no vas a coger uno de cuarenta ni de cincuenta, tienes que cogerlo con setenta; ¿Y con setenta qué hay?, ¿qué es lo que esperamos?...

Con barriga, sin pelo... Ja, ja, ja, ja.

Con barriga. Ja, ja, ja, ja.

... ¿Qué es lo que esperamos? ¡Problemas! ¡Pues para tener por dos problemas, tenemos uno! Eso es lo que yo pienso, eso es lo que yo pienso.

Claro (GR8:55-56).

\subsection{Para las viudas, es algo innecesario.}

Por otro lado, entre las propias viudas existe la convicción de que aquellas mujeres de su edad dispuestas a emparejarse lo que persiguen es, ante todo, obtener compañía. Según afirman, quienes acceden a casarse o a cohabitar con un hombre lo hacen porque son incapaces de soportar la soledad, especialmente de noche, asumiendo no obstante un enorme riesgo porque la cosa puede acabar saliéndoles mal:

Es que piensan en la cama, y es por compañía, en una palabra.

Y si la compañía tiene dinero mejor todavía.

Pero si la compañía te sale mal, y si estás acostumbrada a lo bueno y te sale mal ¿qué?, así que menor sola. Por si acaso, ¿eh?, por si acaso. Por si acaso, mejor sola.

Sí señor. Yo tampoco no... Fueron 43 años... Que no se olvida tan fácil.

Pero es que después, si fue mal con el primero y van al segundo y también le sale mal...

Que todavía buscan al tercero.

$\mathrm{Y}$ van de ligues (GR3:16). 
Es un argumento contrario al establecimiento de otra unión que aparece exclusivamente en el discurso femenino; un argumento que, según interpretamos, contiene una crítica dirigida no tanto hacia los varones que desean emparejarse sino hacia aquellas mujeres mayores que lo intentan. Se les reprocha su decisión argumentando que, con un poco de aguante, no es menester recurrir a ningún hombre por culpa de la soledad. Para lograr compañía, además, siempre puede recurrirse a la familia:

Vamos, yo coger ahora, después de quedar viuda, un marido, sería hundirme. Estoy a gusto. Cuando no tengo con quien hablar cojo el teléfono, y tengo tres hijos, tengo seis nietos, que todos son mayores y puedo hablar con todos...

Eso es lo que me pasa a mí. Si me encuentro sola llamo a los nietos y se ha acabado.

... Y yo me quedo feliz y contenta. Y otros días a lo mejor me llaman ellos " $m a-$ má que hoy no hablé contigo, ¿te pasa algo? ¿estás mal o estás...?”. Me llaman y “¿qué tal?”, digo "bien”, dicen "bueno pues cuelgo, ¿no?”, "pues cuelga” (GR4:32).

No hay nada mejor que la compañía de los familiares, subrayan las mujeres, aunque no se conviva con ellos. Y compañía también puede lograrse a menudo de las vecinas y las amigas. Allá donde el hábitat lo permite, las viudas suelen rodearse de un entramado relacional en torno al domicilio, transcendental en el curso diario de la vida. Dado que los varones no disponen tanto de este recurso (en casa de una viuda sola entra y sale habitualmente cualquier mujer pero en la de un viudo solo no es común ver a hombres, ni mucho menos a mujeres ajenas a la familia), se les percibe como faltos de compañía. Los viudos, víctimas más frágiles de la soledad, tendrían en general más necesidad de rehacer su vida de pareja, mientras que las viudas se las apañan perfectamente solas y no requieren de ningún hombre:

Las parejas de ahora son, de verdad, de conveniencia.

¿Sí?

De conveniencia. No es como cuando se tiene un novio y lo vas conociendo y le vas cogiendo cariño...

¡Hombre!

El padre de tus hijos.

¡Ahí, ahí! jer...

... Pero ahora es conveniencia. Y el hombre necesita más a la mujer que la mu-

Al hombre.

... Al hombre. Una mujer se defiende muy bien sola y no le pasa nada... Sí.

Una mujer sola... Una mujer sola se defiende mejor que un hombre solo.

... Y una vecina... una vecina viene, una vecina buena viene, y si estás mala te trae un plato de comida, ¿eh?...

Lo que sea, sí.

... O lo que sea, pero a un hombre no. A la mujer... al hombre le hace más falta la mujer que a la mujer el hombre.

Porque la vecina dice: "no voy a ese hombre que está solo que me van a criticar". Porque: "van a hablar de mí” (GR7:61:62). 
En este sentido, los hombres suelen valorar menos desfavorablemente la posibilidad de volverse a unir en pareja. En nuestro estudio hemos encontrado a varios que confiesan estar dispuestos a ello, incluso a algunos que lamentan que no les surjan oportunidades; sirva de muestra este par de testimonios:

$¿$ ¿Su hija la tiene cerca entonces?

A seis kilómetros. Claro, y trabaja aquí en Gijón, y bien. Y bueno, y estoy viviendo solo, pero yo la vida mía de solo no es. No estoy porque me guste. Si yo encuentro a una persona que coincidiera conmigo, porque es difícil a esta edad, pues entonces yo cambiaría la vida. Lo digo de corazón (GR2:3-4).

Y otra cosa que quería preguntarles, ¿̇lo de rehacer la vida con otra mujer...?

Hombre yo, no sé, pero si yo encontrara una persona que me agradara y yo le agradara a ella, y fuera una mujer... buena mujer y eso, yo no tendría inconveniente de meterla en mi casa e inclusive casarme, pero...

Sí, claro, claro, pero eso no se encuentra (GR6:33).

\subsection{La negativa de las viudas a sacrificar libertad e independencia}

Las mujeres mayores viudas, al tiempo que se muestran comprensibles hasta cierto punto con la decisión masculina de buscar pareja, advierten sobre otro matiz clave para comprender por qué son tan pocas las que optan por ello: sospechan que los varones de su edad deseosos de unirse a una mujer no sólo persiguen compañía sino que, tanto o más, lo que ansían es disponer permanentemente de alguien que les sirva en casa y les cuide si enferman:

El hombre mayor fue educado... Por la educación que recibieron no se arreglan en casa. Entonces hay muchos que por la compañía y por tener quien les haga las cosas...

Sí, sí.

... porque necesitan ayuda, también buscan una mujer.

Ya, pero si usted se enamora de un hombre y no se casa con él, vive con él pero le dice: "no te voy a cocinar, no te voy a comprar o vamos a repartir...". Usted le podría decir eso.

¿Que se divorcian antes de tiempo! ría.

Y habría quien diría “¿entonces yo para qué te quiero?”. Eso habría quien lo di-

Antes de irse a vivir juntos están divorciados. ¿Los hombres? Ja, ja, ja.

No, habrá de todo, yo pienso que no.

Claro, habrá de todo.

No, los mayores no hay ningún hombre que sepa hacer nada en casa.

No, ninguno.

No, los mayores no.

Porque los han acostumbrado para que los atiendan en su casa (GR4:37).

La socialización recibida, basada en el tradicional reparto de roles dentro de la pareja, hace que muchas mujeres sientan como una obligación dedicarse de pleno a las tareas domésticas y al marido. Hay viudas que así lo han hecho durante varias 
décadas, siendo conscientes de que si volvieran a unirse a un hombre habrían de desempeñar de nuevo esa función, con el agravante de que el compañero no se hallaría en su juventud sino en su vejez, existiendo el riesgo de que enfermara y precisara una ocupación más o menos intensa. Aceptando otra pareja, consideran las viudas, se crearían un problema:

Como uno que hay allí en el barrio, Eduardo. Cada vez que me ve: “ $¡ m e$ da usted una alegría cada vez que la veo!”.

¿Los hombres que van buscando entonces, los hombres que se emparejan?

Una enfermera.

Hombre claro.

Una que lo cuide.

Una enfermera y una criada.

Y para que le preparen la comidita, le preparen la ropita...

Le planchen la ropita, le laven los calzoncillos.

Claro, porque están acostumbrados a otra vida, en la que siempre la mujer ha cuidado al hombre, ¿entiendes?

Claro.

$\mathrm{Y}$ ya eso no se estila.

A mí me lo dijo este señor, dice: "para que me cuide y yo cuidarla a ella". Digo: "hombre claro", pero le dije: "no, yo no".

Sí, sí, claro (GR8:65-66).

Dan por hecho que así habrían de obrar porque la posición que cada género ocupa dentro de la pareja no suele ser un asunto debatido internamente, en efecto, sino que continúa rigiéndose por la costumbre. Entonces, se cuestionan las viudas, ¿para qué volverse a emparejar? No les interesa adoptar ese camino, de ahí que suelan rechazar a los pretendientes cuando surgen:

Yo a mí hace dos años, en la comida de la FOAM me salió... vamos, un señor, ¿no?, que es de Guillena, y ya pues fuimos una vez a desayunar, y dijo que él quería una compañía... vamos, una persona para que lo cuidara...

Para vivir con ella.

Para unirse.

... Para cuidarse, y él cuidarla a ella, ¿̇no? Y digo: "pues mire usted, búsquese usted a una más joven”...

Ja, ja, ja.

Ja, ja, ja, ja (GR8:63).

Según creen, en la esfera doméstica la nueva relación entrañaría un intercambio bastante desigual de tareas y ayudas, como probablemente ocurriera en su anterior matrimonio. De acceder a ella, temen verse obligadas a ocuparse del varón, debiendo renunciar a la libertad y a la independencia que gozan ahora. Sería una forma de esclavizarse, apunta el discurso femenino, de desaprovechar la autonomía que ahora poseen:

¡Bueno y en cambio están así, viviendo juntos, porque no soportan la soledad! ...

Y lo veo bien, yo no lo veo mal. 
Pues mira, ha habido casos que llaman a Juan y Medio, y aquella noche van y se acuestan juntos. Hay que ver lo que hay que tener, ¿eh?

Ojú, ojú.

... Pero yo no soportaría un hombre en mi casa sin conocerlo, sin saber qué le pongo de comer, qué no le pongo. Porque has conocido la libertad y yo ya no quiero un hombre (GR7:56).

\subsection{Lealtad eterna al primer (y único) cónyuge}

Como estamos poniendo de manifiesto, comenzar otra relación de pareja despierta un interés muy escaso entre las mujeres mayores viudas puesto que supone una opción con muchos más inconvenientes que ventajas. A su rechazo viene a añadirse otro importante motivo: si aceptaran a otro hombre en sus vidas, según creen, deshonrarían la memoria del esposo que tuvieron. Pesa enormemente el recuerdo del cónyuge fallecido, del que suelen recalcar las virtudes que poseía y los buenos momentos compartidos, e ignorar sus posibles defectos y los malos ratos vividos; por eso no se conciben formando pareja con otra persona:

$¿$ ¿Y ustedes se lo han planteado alguna vez?

Yo no.

Yo no me veo con otra persona. Nunca me vi con otra persona, qué va.

No, no.

No me veo con otra persona. De eso nada.

Yo tampoco (GR3:15).

Si ha pasado poco desde su muerte, aseguran las mujeres, volverse a emparejar es algo en lo que ni se piensa. Pero aunque hayan transcurrido ya varios años de viudedad, décadas incluso, la huella dejada por el marido difícilmente llega a borrarse nunca sino que persiste motivando la voluntad de no establecerse con nadie más en pareja. Existe un sentimiento, muy compartido entre ellas, de no poner a otro hombre en el lugar que correspondía al esposo:

No.

¡Ya mismo!

No, yo no.

No, ni yo tampoco.

Yo tampoco.

Yo en el sitio de mi marido no pongo a nadie (GR8:63).

Para comprender mejor su postura hemos de considerar que su matrimonio suele ser la primera y única relación de convivencia en pareja que han tenido y, para un elevado porcentaje de ellas, su primera y única experiencia de noviazgo. Esta singularidad amorosa en que fueron socializadas las ha marcado para siempre y aleja la posibilidad de que vuelvan a tener pareja a una edad avanzada. Las viudas parecen guardar una lealtad eterna a su cónyuge fallecido, efectivamente, cuya figura tien- 
den a idealizar; a su muerte, confiesan con resignación, se generó un vacío que se antoja imposible rellenar, y menos con otro hombre:

¿Sus maridos qué fueron sus únicos novios o tuvieron antes otros?

Yo nada más que un novio. Desde chica, desde la Guerra era mi novio.

Y el mío también fue el único.

Yo estuve siete años de novia y no conocí más. Mi marido y se acabó.

Yo el único, cinco años de novio y 25 casada.

Yo estuve cuarenta y... casi cincuenta años casada y no conocí nada más ni he conocido nada más.

Pues yo ocho meses de novia, y vamos, maravilloso, vamos... si volviera a nacer me volvería a casar con el mismo. Yo para mí no hay otro igual.

Yo también.

Vamos, que no busca usted a otro.

No, porque ya iba a estar todo el día con su nombre en la boca.

Yo no, yo no, yo no, yo no.

¡Anda ya! Y: “¿dónde has estado?”, “¿por qué has tardado?”, “ya no tengo más dinero, pon tú la mitad”...

No, no, no, no. A mí mi marido fue muy bueno conmigo y no (GR7:59-60).

Relación de pareja solamente ha de tenerse una en la vida y en sus casos ya es historia, dictan los discursos, una historia que no se quiere olvidar ni menos aun reemplazar por otra. La firmeza con que se han aferrado a esta idea ha privado a muchas mujeres de rehacer su vida en pareja, aunque enviudaran siendo jóvenes. Y menos todavía piensan en casarse ahora, cuando son ya septuagenarias u octogenarias y están más o menos acostumbradas a la soledad. El pasado conyugal, por breve que fuere y lejano que quede en el tiempo, mantiene una huella perenne. $\dot{¿} Y$ qué sucede en esos otros casos en los cuales lo que persiste no es el recuerdo satisfactorio de aquella relación sino todo lo contrario? Hablamos de mujeres que arrastraron graves problemas en su matrimonio, que quizás fueron víctimas de malos tratos y que interpretan la viudez como una liberación:

Yo, como por desgracia no tuve un buen marido, pues no tengo esa nostalgia del marido que muere.

\section{¿No tuvo un buen marido?}

No, porque a mí me tocó un marido que al poco tiempo de casados se dio a la bebida y no me valió nada más que para hacerme siete hijos. Yo tuve que criarlos y aunque él era minero, me quedó una mísera paga de minero, porque si él hubiera trabajado y no hubiera estado tanto tiempo de baja, tanto tiempo despedido y cosas así, pues... Para mí la vida fue muy negra, muy negra, y entonces yo, como no tengo un buen recuerdo del marido, pues prefiero no hablar de él. Hablo de mis hijos, que yo sola los eduqué a mi manera y los tengo a todos bien establecidos, bien educados. Les di a todos... no les di carrera, pero les di una educación para defenderse en la vida, y todos tienen negocios y todos están muy bien situados. Y ya le digo, yo si me siento sola, cosa que no... ninguna vez me siento sola, pero si acaso tardo poco en llamarlos... Doy un toque, no necesito llamarlos, les doy un toque y "mamá, qué te pasa”, "mamá qué quieres". Si no, a un nieto, o a un biznieto, que ya tengo tres. Y vivo feliz (GR4:32-33). 
Si la vivencia matrimonial no fue agradable, en absoluto atrae la idea de volverse a unir a alguien, no sea que se repita la historia. Pero si fue excelente, declaran las viudas, tampoco apetece demasiado buscar a otra persona porque probablemente sería incapaz de hacerlas tan dichosas como el primer cónyuge. Las comparaciones serían inevitables y, habiendo tenido "un marido bueno", el segundo llevaría desde el principio todas las de perder. ¿Interesa, entonces, arriesgarse?:

Pero mira, hay una cosa. Si tú tuviste un marido malo, vamos, no te coges a otro de ninguna manera...

De ninguna manera, eso es lo que iba a decir.

... Y si tuviste un marido bueno, que eso a mí me pasó, porque era muy buena persona y lo echo de menos... ¿ ¿Pero dónde me cojo yo a otro paisano que empiece a comparar? “ ‘Coño, éste... i”, ijolines, si fuera el mío no hacía esto!”. Entonces, ¿para qué te vas a enganchar a eso... y sufrir? (GR4:33).

\subsection{Temor a la reacción contraria de la familia y a la crítica social}

Pensar en la reacción de la familia refuerza la respuesta negativa. Iniciar una relación de pareja supone la toma de una decisión que requiere, en general, la consulta y aprobación de los hijos y las hijas, y quizás de otros parientes. Sus respuestas cuentan y no siempre concuerdan con la voluntad de aquellas personas mayores que pudieran interesarse por ello. He aquí una potencial fuente de conflicto, donde la herencia se sitúa a menudo como problema de fondo. El miedo a que se deterioren los lazos familiares es, en este sentido, otra importante razón que las viudas consideran a la hora de rechazar cualquier oportunidad que surja de casarse o cohabitar con otro hombre:

Hace unos años hubo algo pero no, no me convenía. Bueno, porque no salió la cosa bien, pero ya no. Ahora ya no, ya es muchos años. Ya con mis niños tengo de sobra ya.

Yo me quedé con 53 años y con cuatro hijos, viuda, y me salieron muy buenos partidos, gente de dinero, y digo: "¿yo a mi hijo le voy a poner un padrastro, y tenga que aguantar yo lo que es el tío ese de...?”. Le dije que no, que no, que no. Y todavía voy por ahí y me salen así. Ja, ja, ja. Todavía me salen pretendientes (GR7:55).

El temor a que la familia reaccione mal también aparece en el discurso masculino. Los viudos creen que si empezaran otra relación de pareja se expondrían a la incomprensión de sus seres queridos, arruinando probablemente el bienestar relacional que mantienen con ellos ahora. Tener hijos pequeños cuando sobrevino la viudez es otro argumento esgrimido para no haber rehecho, en su momento, la vida junto a otra mujer:

Pues yo llevo tres años aquí, que mis intenciones son esas, de buscar una mujer, y...

Yo tuve una compañera precisamente en el trabajo, compañera mía en el trabajo, que era francesa, y podía haberme casado, pero... Ella sabía mi situación. Ella sabía mi situación, pero... Era una buena muchacha, soltera también. Yo la conocía de 
unos pocos de años ya trabajando con ella, pero yo pensaba en muchas cosas. Yo pensaba entonces: "bueno, yo tengo cinco hijos; yo meto esta mujer en mi casa; mis hijos no sé cómo la van a aceptar...”.

Eso es muy problemático.

“... No sé cómo la van a aceptar”. Y tú no puedes meter a una mujer en tu casa y luego irte a tu trabajo y a lo mejor estar pendiente de lo que pasa en tu casa o de lo que no pasa en tu casa. Son cosas que eso cada uno, cada uno ve la situación de una forma. Yo he tenido... tuve mi oportunidad y la desprecié. No la quise, no la quise, por eso.

A lo mejor fue para bien (GR5:16).

Unirse a alguien comportaría ese riesgo, tanto para los viudos como para las viudas, y además les expondría a sufrir otra desagradable experiencia, máxime en el medio rural: convertirse en la comidilla del vecindario o las amistades, ser objeto de la crítica social. Según De Miguel (2002:199), “lo que compete a cada edad es un estereotipo basado en la experiencia y también en la norma de lo que socialmente resulta aceptable”. De ahí la crítica que suele afectar a aquellas personas mayores que dejan de representar el papel de viudos o viudas que les ha sido asignado e intentan hacer lo que los jóvenes: formar una pareja. Véase, si no, cómo son tratadas las relaciones sentimentales que establecen personajes de gran notoriedad pública:

Usted Josefa dice que tampoco, ¿no?

¿Casarme? Je, je, je ¡Como la Duquesa de Alba!

Ja, ja, ja, ja.

Ja, ja, ja, ja.

Ja, ja, ja, ja.

¡Ay Dios!

Desde luego... (GR3:16).

Es otra clave más para comprender por qué se desecha la opción de buscar pareja. No se quiere dar que hablar en el pueblo o en el barrio. El discurso femenino se muestra al respecto mucho más precavido, quizás, cabe reiterar, porque la crítica de las viudas se orienta esencialmente hacia sus iguales. Además, suelen asociarse los noviazgos con la participación habitual en "bailes” y "viajes”, como los que organizarían los hogares o clubs de jubilados, encubriendo a quienes pretendieran intimar. Es un presupuesto que vienen a reforzar los contenidos de algunos programas de televisión:

¿Dónde se empareja la gente, donde encuentran a la pareja, los que se emparejan?

Bueno, en muchísimos sitios.

En el programa de Juan Y Medio...

En el hogar hay también muchas parejas.

... Y en el hogar. Je, je, je.

En el hogar, en los bailes.

$\mathrm{Y}$ en los bares... Y en los viajes (GR7:60-61). 


\section{Discusión y conclusiones}

El objetivo que nos planteamos en este artículo era analizar el discurso de las personas mayores viudas respecto a la posibilidad de rehacer su vida de pareja. El Movimiento Natural de la Población (INE) confirma, año tras año, que las bodas con participación de personas mayores viudas son algo residual en España, y prácticamente lo mismo hay que afirmar de las uniones de hecho, a tenor de los datos de encuesta que informan de ellas. Los materiales de campo obtenidos en nuestra investigación cualitativa, realizada con personas mayores que viven solas (fundamentalmente viudas y de edad superior a los 75 años), nos han permitido interpretar por qué resulta tan infrecuente el fenómeno. Su análisis ha puesto de relieve una postura de profundo rechazo, sobre todo por parte de las mujeres, que no se fundamenta en un único motivo sino sobre un cúmulo de ellos.

Algunos de esos motivos parecen sostenerse en valores tradicionales, como el no querer poner a otro hombre en el lugar del esposo fallecido. La lealtad que se guarda hacia él se entiende mejor si consideramos que suele tratarse de la única relación de convivencia en pareja que han tenido en sus vidas. Investigaciones hechas en países tan diversos como Estados Unidos (Lopata, 1981), Japón (Ogawa y Retherford, 1997) u Holanda (Stevens, 2002) también han concluido que el apego al cónyuge que se tuvo es un factor decisivo para que las mujeres mayores viudas no se interesen por otra relación; la primera tiende a recordarse eternamente, aunque no siempre en términos positivos puesto que tampoco debe ignorarse que hay viudas que han atravesado por una desagradable experiencia matrimonial y que no quieren arriesgarse con otra. Un segundo factor que, en principio, puede interpretarse en clave tradicional, es la idea manifiesta de que formar una pareja no es apropiado para las personas de su edad; indagando en los discursos, sin embargo, descubrimos que tal excusa conlleva el rechazo de las viudas a aceptar una discriminación de género conectada, a su vez, con la institucionalización de las edades sociales: la norma que las obliga a emparejarse con hombres (mucho) mayores que ellas. Se atisba aquí, por primera vez, una resistencia a la mera reproducción de un orden social y unas reglas de juego tradicionales que estas mujeres entienden que les colocan en una posición desfavorable.

De esta realidad percibida se derivan dos firmes convicciones. Una, que aquellas viudas que deciden, no obstante, emparejarse son incapaces de soportar la soledad, es decir, se trata de mujeres que requieren imperiosamente la compañía masculina; otra, que, como la compañía pueden lograrla de la familia, las vecinas o las amigas, las mujeres mayores no tienen necesidad de buscar otra pareja: son autosuficientes en todos los órdenes. Cosa distinta pasaría con los viudos, que son vistos como faltos de apoyo, y no sólo de tipo emocional: las viudas sospechan que el interés de los hombres por buscar pareja responde, más que nada, a su estrategia por encontrar a alguien que les atienda en casa y les cuide si enferman. De acceder ellas a este reclamo, temen que lo que les esperaría es la obligación de dedicarse a esa otra persona, quizás como ocurrió durante décadas en su matrimonio. Al igual que constataron estudios realizados en Estados Unidos (Talbott, 1998) y el Reino Unido 
(Davidson, 2001), en el nuestro queda claro que ocuparse de otro hombre es una responsabilidad con la que las mujeres mayores viudas no quieren cargar. No les interesa adoptar esta vía de intercambio desigual de derechos y deberes, máxime cuando se expondrían además a ser incomprendidas por la familia y criticadas en el entorno social. Otra señal de la resistencia al tradicionalismo de la que hablábamos arriba.

En definitiva, pensamos que, más allá de la fuerza de la tradición, las reticencias de las mujeres mayores viudas a unirse a otro hombre obedecen, en lo esencial, al deseo que sienten de no perder su libertad y su independencia. Ésta es la principal aportación de nuestro trabajo. Socializadas desde la infancia bajo la dominación masculina, su vida ha solido transcurrir bajo el sometimiento: primero a la autoridad paterna y luego a la del marido. Creen que si accedieran a emparejarse de nuevo volverían a delegar buena parte de su autonomía en otra persona. En términos generales, han aprendido a definir su personalidad más allá del matrimonio, habiendo pasado a decidir por sí mismas acerca de todo lo que les compete y a dedicarse un tiempo que antes habían destinado a los demás (a los padres, a los hijos, al cónyuge). Este "control percibido" de su existencia, como lo denomina Freixas (2004:341), es clave en su bienestar actual.

En teoría, la viudedad no supone una situación irreversible; en la práctica, sin embargo, cuando una mujer mayor atraviesa por ella desecha la idea de buscar otro hombre. Y ello porque la pérdida del cónyuge, pese a ser un evento traumático, sitúa a muchas de estas mujeres ante un desafío: la necesidad de vivir la vida propia. $\mathrm{Al}$ acometerlo, resulta probable que hayan experimentado sentimientos inéditos de signo diverso, unos negativos y otros positivos, que se hayan topado con problemas nuevos pero, a la vez, puede que hayan descubierto derechos (como la libertad y la independencia) que previamente apenas tuvieron ocasión de disfrutar. Uniéndose a otro hombre, apuntan unánimemente los discursos, los sacrificarían. Por eso, el posible dilema entre obtener compañía (rehaciendo su vida de pareja) o continuar disfrutando de esos derechos (aunque sea solas en casa) ni llega a plantearse. Para nosotros, todo esto no es sino un indicio de algo que ha permanecido más bien invisible en los análisis en torno a la viudedad en la vejez: las actuales mujeres mayores viudas, en general, mucho más que portadoras de la tradición, son protagonistas de una transformación sin precedentes en España, tanto en la concepción de la viudedad y de la vejez como en las relaciones entre los géneros.

Si entre las viudas existe una actitud de rechazo prácticamente generalizada, que tiene su reflejo a nivel estadístico en el escasísimo número de ellas que vuelven a casarse o se establecen en uniones de hecho, entre los viudos, sin embargo, la idea de emparejarse de nuevo genera una variedad de respuestas: hay quienes estarían dispuestos a hacerlo de inmediato, quienes no descartan rehacer su vida de pareja pero tampoco lo buscan activamente y quienes renuncian a ello por completo. Es decir, no existe una postura colectiva definida, como ocurre con las viudas, sino más bien planteamientos diversos. Sin que pongan la edad como excusa para unirse a otra mujer ni sugieran que la relación entrañaría un intercambio desigual de obligaciones y derechos, el interés manifiesto por encontrar pareja obedece, cuando se 
tiene, a la necesidad que sienten algunos viudos de combatir la soledad y, quizás también, a su estrategia por lograr una atención material tanto en el presente como en el futuro; $y$, cuando no se tiene, lo que prima es el recuerdo de la esposa fallecida así como la voluntad de no arriesgar el bienestar relacional con la familia, especialmente con los hijos y/o las hijas, aunque cabría añadirse que una vez que se han acostumbrado a vivir solos tampoco sienten la necesidad imperiosa de unirse a nadie.

La investigación que hemos llevado a cabo tiene, no obstante, algunas limitaciones. En primer lugar, no aborda (porque no fueron suscitadas por los viudos y las viudas en los grupos de discusión) las relaciones 'living apart together' (LAT) o “parejas de doble residencia”, como las denomina De Singly (2000), que no implican necesariamente una convivencia de continuo. Y ello pese a su importancia creciente entre los procesos de emparejamiento en la vejez, como ha sido destacado (Ayuso, 2012; Calasanti y Kiecolt, 2007; Levin, 2004; De Jong y Peeters, 2003; Karlsson y Borell, 2002). En segundo lugar, nuestro análisis deja de lado a un perfil social en auge: las personas mayores separadas o divorciadas (Brown y Lin, 2012; Kalogirou y Murphy, 2006). Aunque apenas representen en España alrededor del 3\% de las personas de 65 o más años, sus actitudes y comportamientos podrían resultar menos desfavorables hacia la posibilidad de rehacer la vida de pareja, ya sea casándose de nuevo o cohabitando. En tercer lugar, nuestra investigación no diferencia entre las personas mayores viudas por edad, no pudiendo determinar por consiguiente si los discursos tienden a variar dependiendo de si se trata, por ejemplo, de personas recién jubiladas u octogenarias.

Sin embargo, lo que sí ha puesto al descubierto nuestro trabajo ha sido una serie de aspectos novedosos a la hora de entender los motivos del rechazo al emparejamiento por parte de las personas mayores viudas, en especial de las mujeres. Por tanto, y sugiriendo posibles desarrollos futuros, sería conveniente realizar una investigación por encuesta que permitiera, entre otros objetivos, cuantificar el peso que tiene cada uno de los motivos citados sobre la decisión de rechazar la formación de una nueva pareja que las personas mayores viudas nos han transmitido a través de sus discursos, así como su posible asociación estadística con variables como el sexo, la edad, el hábitat, el nivel de estudios, los ingresos, los años transcurridos desde la muerte del cónyuge, la existencia o no de hijos o la dimensiones de las redes vecinales y de amistad.

En general, en el marco de un creciente envejecimiento demográfico y de llegada a la edad de la jubilación de cohortes con tasas de divorcio más elevadas, con un mayor nivel educativo y con una mejor posición económica personal, creemos necesario llevar a cabo nuevas investigaciones sociológicas sobre los procesos de emparejamiento en las edades avanzadas. También otras que permitan contrastar el desarrollo de tales procesos según las distintas fases del curso vital de las personas. 


\section{Bibliografía:}

Alberdi, I. y P. Escario. (1986): Estudio sociológico sobre las viudas en España, Madrid: Ministerio de Trabajo y Seguridad Social.

Alberdi, I. y P. Escario (1990): La situación social de las viudas en España. Aspectos cuantitativos, Madrid: Ministerio de Asuntos Sociales.

Ayuso Sánchez, L. (2011): "Las redes de apoyo social en los procesos de emparejamiento en la viudedad en España”, en Félix Requena (coord. y ed.): Las redes de apoyo social, Navarra: Thomson Reuters.

Ayuso Sánchez, L. (2012): "Living apart together en España. ¿'Noviazgos o parejas independientes?”, Revista Internacional de Sociología, 70 (3): 587-613.

Bideau, A. (1980): "A demographic and social analysis of widowhood and remarriage: the example of the Castellany of Thoissey-en-Dombes, 1670-1840", Journal of Family History, 5 (1): 28-43.

Blom, I. (1991): "The history of widowhood: a bibliographic overview", Journal of Family History, 16 (2): 191-210.

Bograd, R. y B. Spilka (1996): "Self-disclosure and marital satisfaction in mid-life and late-life remarriages", The International Journal of Aging and Human Development, 42 (3): 161-172.

Bourdieu, P. (2005): “La práctica de la sociología reflexiva”, en: Pierre Bourdieu y Loïc Wacquant (eds.). Una invitación a la sociología reflexiva, Buenos Aires: Siglo XXI Editores Argentina.

Breschi, M. et al. (2009): "Family composition and remarriage in pre-transitional Italy: a comparative study”, European Journal of Population, 25 (3): 277-296.

Brown, S. L. y A. Booth (1996): "Cohabitation versus marriage: a comparison of relationships quality”, Journal of Marriage and Family, 58 (3): 668-678.

Brown, S. L. y S. Kawamura (2010): "Relationship quality among cohabitors and marrieds in older adulthood”, Social Science Research, 39 (5): 777-786.

Brown, S. L. e I. Lin (2012): "The gray divorce revolution: rising divorce among middle-aged and older adults, 1990-2010”, Journal of Gerontology: Social Sciences, 67B (6): 731-741.

Brown, S. L.; J. Roebuck y G. R. Lee (2005): "The significance of nonmarital cohabitation: marital status and mental health benefits among middle-aged and older-adults”, Journal of Gerontology: Social Sciences, 60B (1): 21-29.

Brown, S. L.; G. R. Lee y J. R. Bulanda (2006): "Cohabitation among older adults: a national portrait”, Journal of Gerontology: Social Sciences, 61B (2): 71-79.

Brown, S. L.; J. R. Bulanda y G. R. Lee (2012): "Transition into and out of cohabitation in later life”, Journal of Marriage and Family, 74 (4): 774-793.

Buckley, C. J. (1996): "Gender, age and the marriage market: evidence on marriage in late adulthood in Russia”, Journal of Cross-Cultural Gerontology, 11 (3): 255-267.

Bulcroft, K. A. et al. (1989): “Antecedents and consequences of remarriage in later life”, Research on Aging, 11 (1): 82-106. 
Bumpass, L.; J. A. Sweet y T. Castro Martín (1990): "Changing patterns of remarriage”, Journal of Marriage and Family, 52 (3): 747-756.

Burch, T. K. (1990): "Remarriage of older Canadians. Description and interpretation”, Research on Aging, 12 (4): 546-559.

Calasanti, T. y K. J. Kiecolt (2007): "Diversity among late-life couples”, Generations, 31 (3): 10-17.

Carr, D. (2004): "The desire to date and remarry among older widows and widowers”, Journal of Marriage and Family, 66 (4): 1051-1068.

Castro Martín, T. (2003): "Matrimonios de hecho, de derecho y en eterno aplazamiento. La nupcialidad española al inicio del siglo XXI”, Sistema, 175-176: 87112.

Castro Martín, T. y M. Domínguez Folgueras (2008): “Matrimonios 'sin papeles': perfil sociodemográfico de las parejas de hecho en España según el Censo de 2001”, Política y Sociedad, 45 (2): 49-71.

Cherlin, A. J. (2010): "Demographic trends in the United States: a review of research in the 2000s", Journal of Marriage and Family, 72 (3): 403:419.

Chevan, A. (1996): "As cheaply as one: cohabitation in the older population", Journal of Marriage and Family, 58 (3): 656-667.

Clarke, S. C. y B. F. Wilson (1994): "The relative stability of remarriages. A cohort approach using vital statistics”, Family relations, 43 (3): 305:310.

Coleman, M. y L. H. Ganong (1990): “Remarriage and stepfamily in the 1980's: increased interest in an old family form”, Journal of Marriage and Family, 52 (4): 925-940.

Coleman, M.; L. H. Ganong y M. Fine (2000): "Reinvestigating remarriage: another decade of progress”, Journal of Marriage and Family, 62 (4): 1288-1307.

Cooney, T. M. y K. Dunne (2001): "Intimate relationships in later life. Current realities, future prospects”, Journal of Family Issues, 22 (7): 838:858.

Davidson, K. (2001): "Late life widowhood, selfishness and new partnership choices: a gendered perspective”, Ageing and Society, 21 (3): 297-317.

Davidson, K. (2002): "Gender differences in new partnerships choices and constraints for older widows and widowers”, Ageing International, 27 (4): 43-60.

De Jong Gierveld, J. (2002): "The dilemma of repartnering: considerations of older men and women entering new intimate relationships in later life", Ageing International, 27 (4): 61-78.

De Jong Gierveld, J. (2004): "Remarriage, unmarried cohabitation, living apart together: partner relationships following bereavement or divorce". Journal of Marriage and Family, 66 (1): 236-243.

De Jong Gierveld, J. y A. Peeters (2003): "The interweaving of repartnered older adults' lives with their children and siblings”, Ageing and Society, 23 (2): 187205.

De Miguel, A. (2002): El espíritu de Sancho Panza. El carácter español a través de los refranes, Madrid: Espasa Calpe.

De Singly, F. (2000): Libres ensemble. L'individualisme dans la vie commune. París: Nathan. 
Delbès, C. y J. Gaymu (2000): “Du veuvage à l'isolement”, Gérontologie et Société, 95: 11-26.

Delbès, C. y J. Gaymu (2005): "L’histoire conjugale des 50 ans et plus”, en Cécile Lefèvre y Alexandra Filhon (dirs.): Histoire de familles. Histoires familiales, París: INED.

Denzin, N. K. e Y. S. Lincoln (2012): "Introducción general. La investigación cualitativa como disciplina y como práctica”, en Norman K. Denzin e Yvonna S. Lincoln (coords): El campo de la investigación cualitativa, Barcelona: Gedisa.

Domínguez Folgueras, M. y T. Castro Martín (2013): "Cohabitation in Spain: no longer a marginal path to family formation", Journal of Marriage and Family, 75 (2): $422-437$.

Elman, C. y A. S. London (2002): "Sociohistorical and demographic perspectives on U.S. remarriage in 1900". Social Science History, 26 (1): 199-241.

Fauve-Chamoux, A. (2010): "Revisiting the decline in remarriage in early-modern Europe: the case of Rheims in France”, The History of the Family, 15 (3): 283297.

Freixas Farré, A. (2004): “Envejecimiento y perspectiva de género”, en Ester Barberá e Isabel Martínez (comps.): Psicología y género, Madrid: Pearson Prentice Hall.

Glaser, B. G. y A. L. Strauss (1999): The discovery of Grounded Theory: strategies for qualitative research, New York: Aldine de Gruyter.

Glick, P. C. (1980): "Remarriage. Some recent changes and variations", Journal of Family Issues, 1 (4): 455-478.

Iglesias de Ussel, J. et al. (2001): La soledad en las personas mayores: influencias personales, familiares y sociales. Análisis cualitativo, Madrid: IMSERSO.

Kalogirou, S. y M. Murphy (2006): "Marital status of people aged 75 and over in nine EU countries in the period 2000-2030", European Journal of Population, 3 (2): 74-81.

Karlsson, S. G. y K. Borell (2002): "Intimacy and autonomy, gender and ageing: living apart together”, Ageing International, 27 (4): 11-26.

King, V. y M. E. Scott (2005): "A comparison of cohabiting relationships among older and younger adults”, Journal of Marriage and Family, 67 (2): 271-285.

Levin, I. (2004): “Living apart together: a new family form”, Current Sociology, 52 (2): 223-240.

Lin, I. y S. L. Brown (2012): "Unmarried boomers confront old age: a national portrait”, The Gerontologist, 52 (2): 153-165.

Lopata, H. Z. (1981): "Widowhood and husband sanctification”, Journal of Marriage and Family, 43 (2): 439-450.

López Doblas, J. (2005): Personas mayores viviendo solas. La autonomía como valor en alza, Madrid: IMSERSO.

Mahay, J. y A. C. Lewin (2007): “Age and the desire to marry”, Journal of Family Issues, 28 (5): 706-723.

Martínez Pastor, J. I. (2009): Nupcialidad y cambio social en España, Madrid: Centro de Investigaciones Sociológicas. 
Meil Landwerlin, G. (2003): Las uniones de hecho España, Madrid: Centro de Investigaciones Sociológicas.

Miret Gamundi, P. (2007): "¿Son diferentes las uniones consensuales y los matrimonios? Comparación de los censos españoles de población de 1991 y 2001”, Revista Internacional de Sociología, 48: 55-74.

McQuillan, K. (2003): "Family composition and remarriage in Alsace, 1750-1850", Journal of Interdisciplinary History, 33 (4): 547-567.

Moorman, S. M.; A. Booth y K. L. Fingerman (2006): "Women's romantic relationships after widowhood”, Journal of Family Issues, 27 (9): 1281-1304.

Moring, B. (2002): "Widowhood options and strategies in preindustrial northern Europe: socioeconomic differences in household position of the widowed in 18th and 19th century Finland”, The History of the Family, 7 (1): 79-99.

Moustgaard, H. y P. Martikainen (2009): "Nonmarital cohabitation among older finnish men and women: socioeconomic characteristics and forms of union dissolution”. Journal of Gerontology: Social Sciences, 64B (4): 507-516.

Noël-Miller, C. M. (2011): "Partner caregiving in older cohabiting couples". Journal of Gerontology: Social Sciences, 66B (3): 341-353.

Ogawa, N. y R. D. Retherford (1997): "Shifting cost of caring for the elderly back to families in Japan: will it work?, Population and Development Review, 23 (1): 59-94.

Sánchez Vera, P. y M. Bote Díaz (2007): Los mayores y el amor, Valencia: Nau Llibres.

Sánchez Vera, P. et al. (2009): Viudedad y vejez. Estrategias de adaptación a la viudedad de las personas mayores en España, Valencia: Nau Llibres.

Sassler, S. (2010): "Partnering across the life course; sex, relationships, and mate selection”, Journal of Marriage and Family, 72 (3): 557-575.

Schmidt, A. (2007): "Survival strategies of widows and their families in early modern Holland, c. 1580-1750", The History of the Family, 12 (4): 268-281.

Smith, K. R.; C. D. Zick, y G. J. Duncan (1991): "Remarriage patterns among recent widows and widowers”, Demography, 28 (3): 361-374.

Spijker, J. (2007): “Trayectorias familiares después de la viudedad en España. Marco teórico y factores determinantes”, Papers de Demografía 326: 1-53.

Stevens, N. (2002): "Re-engaging: new partnerships in later-life widowhood", Ageing International, 27 (4): 27-42.

Strauss, A. y J. Corbin (2002): Bases de la investigación cualitativa. Técnicas y procedimientos para desarrollar la teoría fundamentada, Medellín: Editorial Universidad de Antioquía.

Talbott, M. M. (1998): “Older widows' attitudes towards men and remarriage”. Journal of Aging Studies, 12 (4): 429-449.

Van den Hoonaard, D. K. (2002): "Attitudes of older widows and widowers in New Brunswick, Canada, towards new partnerships”, Ageing International, 27 (4): 79-92.

Van Poppel, F. (1995): "Widows, widowers and remarriage in nineteenth-century Netherlands”. Population Studies, 49 (3): 421-441. 
Watson, W. K.; N. J. Bell y C. Stelle (2010): "Women narrate later life remarriage: negotiating the cultural to create the personal”, Journal of Aging Studies, 24 (4): 302-312.

Wilson, B. F. y S. C. Clarke (1992): “Remarriages. A demographic profile”, Journal of Family Issues, 13 (2): 123-141.

Wu, Z. (1995): "Remarriage after widowhood: a marital history study of older Canadians”, Canadian Journal of Aging, 14 (4): 719-736. 